\title{
Artigo
}

\footnotetext{
Resumo

Neste artigo, procuraremos apontar as diferenças entre o diagnóstico psiquiátrico de corrente biológica o o diagnóstico psicanalitico. Para isso, serão apresentados alguns aspectos da psiquiatria clássica e a psiquiatria biológica, ponderando a influência da psicopatologia na definição dos manuais diagnósticos e, consequentemente, nos diagnósticos utilizados atualmente na clínica psiquiátrica. Discutiremos a finalidade do diagnóstico estrutural sob transferência para traşar a direção do tratamento em psicanálise e pontuaremos as possibilidades de aproximação entre os diagnósticos, considerando o fenômeno e a estrutura. Porfim, utilizaremos o estudo de um caso clínico com nomeações diagnósticas de ambas as vertentes. Descritores: psiquiatria; psicanálise; diagnóstico; direção do tratamento.
}

\section{A SOBERANIA DA CLÍNICA: ALÉM DO DIAGNÓSTICO EM PSIQUIATRIA E PSICANÁLISE}

\author{
Natália Raquel Pereira Loures \\ Paula Brant Fernandes
}

DOl: http://dxdoi.org/10.11606/issn.1981-1624.v20i2p279-295.

\section{Introdução}

A tualmente percebemos que a atuação na clínica psiquiátrica tem se pautado, em grande parte, pelo estabelecimento de diagnósticos. Nesse sentido, os manuais de classificação (Manual Diagnóstico e Estatístico de Transtornos Mentais - DSM e Classificação Estatística Internacional de Doenças

- Psicóloga do Centro de Referência Especializado em Assistência Social (CREAS) de Itaúna, MG, Brasil.

- Psicóloga do Centro de Referência em Saúde Mental/(CERSAM Oeste) e do Centro de Saúde Salgado Filho de Belo Horizonte. Mestranda em Psicologia pela Universidade Federal de Minas Gerais, Belo Horizonte, MG, Brasil. 
e Problemas Relacionados à Saúde - CID) são amplamente utilizados. Há ainda no campo psi a atuação da psicanálise que, embora estabeleça diagnósticos, toma como partida o sujeito e sua forma de posicionamento no mundo. Todavia, muitos têm sido os questionamentos e as dificuldades de conversação entre os diagnósticos psiquiátrico e psicanalítico. Diante disso, torna-se necessário estabelecer a distinção existente entre esses diagnósticos, uma vez que se referem a campos de conhecimento distintos, mas não opostos.

Por meio deste trabalho, objetivamos demonstrar a diferença existente entre os diagnósticos citados, apontando a importância do diagnóstico estrutural para a direção do tratamento. Para tanto, pretendemos utilizar uma pesquisa bibliográfica e clínica, norteada pelos seguintes questionamentos: É possível compararmos dois campos de conhecimento tão diferentes? A psiquiatria tem como herança a mensuração e a classificação para um diagnóstico baseado nos fenômenos observáveis, e a psicanálise é uma teoria que se sustenta a partir do conceito de inconsciente e que apresenta um diagnóstico que não poderá ser dado exclusivamente pelos sintomas e sim em referência à estrutura clínica do sujeito. E ainda: Qual é a contribuição do diagnóstico estrutural para a direção do tratamento e para os efeitos terapêuticos?

No decorrer do artigo procuraremos responder a essas questões, dividindo o trabalho em dois blocos: o diagnóstico psiquiátrico e o diagnóstico psicanalítico, passando por uma discussão sobre o fenômeno e a estrutura. Para isso, nos serviremos de uma vinheta clínica que indicou a insuficiência dos diagnósticos para a obtenção de efeitos terapêuticos. Orientadas pela psicanálise aplicada em uma instituição pública de saúde mental, observamos a soberania da clínica sob transferência para além do estabelecimento de diagnóstico.

\section{As concepções psiquiátricas e o diagnóstico em psiquiatria}

Para tratarmos do diagnóstico em psiquiatria, faz-se necessário apresentar alguns aspectos das concepções predominantes na história desse campo da medicina. Existe a psiquiatria clássica e a psiquiatria biológica, esta como paradigma dominante na prática contemporânea. A psiquiatria foi a primeira disciplina científica a isolar a psique 
e localizar o mental como objeto de estudo e cuidados. Contudo, ela tenta fazer o sujeito entrar no discurso da ciência pela ótica da clínica médica e, portanto, das patologias do mental. Pela via da doença mental, a resposta que a psiquiatria oferece situa-se na mensuração e classificação da sanidade mental e sua terapêutica se refere preferencialmente à medicação dos desvios observados (Sauret, 2003).

Foi a psiquiatria clássica que influenciou diretamente a constituição das entidades clínicas, que vêm sendo utilizadas, modificadas e incluídas nos manuais de classificação. Segundo Vieira (2001), até então existiam algumas classificações de delimitações abrangentes e imprecisas que permitiam a "circulação subjetiva" e que apresentavam poucas possibilidades de categorização, não trazendo como consequência a "natureza eminentemente assubjetivadora" do diagnóstico. $\mathrm{O}$ autor acrescenta que atualmente "esta multiplicação de categorias responde à tentação da ciência de efetuar uma substituição. Considerando todas as marcas do sujeito como sinais do eu ela oculta um sobre o outro e realizando assim seu programa, ou seja, a foraclusão do sujeito" (p. 171).

Os manuais de classificação são constituídos a partir da psicopatologia, a qual, conforme Santos (2008), não é um campo da psiquiatria, mas uma ciência autônoma. Dalgalarrondo (2008) acrescenta: "A psicopatologia em acepção mais ampla, pode ser definida como o conjunto de conhecimentos referentes ao adoecimento mental do ser humano" (p. 27). Nesse sentido, o campo da psicopatologia inclui muitos fenômenos humanos especiais associados ao que se denomina doença mental (Dalgalarrondo, 2008). A psiquiatria utiliza-se das classificações psicopatológicas para a definição do diagnóstico, por preocupar-se com o estabelecimento de conhecimentos sistemáticos sobre as alterações psicopatológicas (Santos, 2008). Para o autor, a psicopatologia é "um instrumento obrigatório de diagnóstico" (p. 28).

A medicina psiquiátrica apropriase das bases psicopatológicas, mas enreda também o seu conhecimento por diversas perspectivas que podem ser a biológica, a comportamental ou outras como as que valorizam as representações socioculturais. Contudo, a psiquiatria biológica alcançou posição de destaque, pois foi a partir dela que esse campo de conhecimento pôde legitimar-se como saber médico, buscando a objetividade e a cientificidade construída e validada na medicina (Santos, 2008).

De acordo com Birman (2001), verifica-se que atualmente a psicofarmacologia influencia e legitima a psiquiatria biológica, fundada nas neurociências e na medicina somática. Assim, o surgimento do diagnóstico psiquiátrico ocorre por intermédio dos psicofármacos, o que é considerado um problema, uma vez que a leitura dos transtornos psíquicos sob 
a ótica de função e disfunção toma "o medicamento como seu operador estratégico por excelência” (p. 23). Nesse sentido, a psiquiatria biológica chega a ser chamada de psiquiatria remedicalizada, sendo que a clínica passa a ser organizada pelos efeitos que podem ser obtidos por meio da medicação (Miller, 1987). Dessa forma, a psiquiatria assume uma posição que reduz o sujeito aos sintomas e o tratamento às substâncias que modifiquem o funcionamento do organismo.

A moderna psiquiatria biológica eliminou completamente a presença da experiência subjetiva do doente no acontecimento da enfermidade. Para a psiquiatria biológica, o sujeito é mero suporte de algo bem mais vasto que lhe acontece e que dele se apossa, advindo de uma disfunção produzida em seu organismo. São, portanto, as variaçóes presentes nos neuro-hormônios que representam as condiçóes de possibilidade das disfunçóes e que substancializam as perturbações do espírito. A história da existência do sujeito nas suas complexas relaçóes com o espaço social em que ele se inscreve deixa de ter qualquer relevância para a leitura do que ocorre na profundidade do organismo, em particular, no funcionamento do sistema nervoso, sempre considerado a partir dos desequilíbrios neuro-hormonais. (Birman, 2001, p. 24).

Assim, a tendência de classificação dos fenômenos de forma objetiva indica-nos um empobrecimento da clínica psiquiátrica. A prova disso é o número de diagnósticos possíveis a partir da utilização da Classificação Estatística Internacional de Doenças e Problemas Relacionados à Saúde - décima revisão (CID-10), elevando o número de classificações em 800 diagnósticos (Figueiredo \& Tenório, 2002). Essa perspectiva biológica, que tem aumentado nos dias atuais, tende a não priorizar a fala do sujeito, mas a descrição dos fenômenos de forma objetiva, perdendo a experiência subjetiva na vivência da enfermidade.

Quinet (2001) aponta a necessidade de diferenciarmos os manuais diagnósticos de manuais de psiquiatria. Embora, na maioria das vezes, a psiquiatria utilize esses manuais, não podemos reduzi-la a eles. "Os manuais de diagnóstico atuais parecem tomados pela preocupação de constituir uma língua comum entre psiquiatras de todo o mundo, como um esperanto que pudesse terminar com o mal-entendido próprio à comunicação" (p. 74). Acreditamos que essa busca por uma universalização da linguagem psiquiátrica acabou ocupando o lugar de destaque na psiquiatria, sendo que o diagnóstico psiquiátrico passou a se constituir exclusivamente pelos critérios diagnósticos estabelecidos nos manuais de classificação.

Para Zarifian (1986/1989) o diagnóstico em psiquiatria pode assumir três diferentes papéis: Pode servir como uma forma de consenso entre os profissionais, possibilitando a comunicação dos mesmos sobre o caso; pode ser utilizado não como um diagnóstico preciso, mas para apontar algumas semelhanças entre os "doentes", a fim de estabelecer uma homogeneidade para fins de pesquisa e, finalmente, como diagnóstico próprio do profissional quando não há a

282 Estilos clin., São Paulo, v. 20, n. 2, mai./ago. 2015, 279-295. 
necessidade de comunicação e esse não se utiliza dos sistemas de convenção para estabelecer o diagnóstico. De acordo com o autor, em todos os casos a presença ou a falta do diagnóstico dependerá do objetivo procurado.

Conforme Kammerer e Wartel (1986/1989), o diagnóstico possibilita definir a gravidade do estado, estabelecer a direção do tratamento, decidir pela psicoterapia ou farmacologia, avaliar os riscos, dentre outras opções. Contudo, os autores advertem que o diagnóstico pode ter validade relativa ou temporária, e que "as categorias nosográficas são úteis para uma primeira abordagem do paciente" (p. 32).

Nesse sentido, o diagnóstico psiquiátrico torna-se "subordinado ao conjunto de inferências que forma a posição teórica do psicopatólogo ou psicoterapeuta" (Santos, 2008, p. 30). Rubinstein (2014) pondera que cada profissional ordena os fenômenos que se apresentam na clínica a partir dos seus referenciais teóricos. "Cada teoria corta o campo particular dos fenômenos clínicos de forma diferente"1 (p. 3, tradução nossa). Assim, o diagnóstico não deriva de posições pessoais, podendo indicar os limites da teoria.

Os limites do diagnóstico psiquiátrico não estão definidos apenas em termos de certo relativismo subjetivo, que considera cada pessoa uma realidade inatingível e única; estão na realidade limitados também pelo grau de subjetividade do construto diagnóstico que é uma "criação" humana. (Santos, 2008, p. 30).

Uma das limitações do diagnóstico psiquiátrico, na corrente biológica, seria a perda da dimensão clínica no que diz respeito à direção do tratamento, devido à necessidade de mantermos o foco no sujeito. Como assinala Sauret (2003), “....sem dúvida, os pesquisadores pensam conseguir, assim, um tratamento objetivo do dito sujeito, sem perceberem que reiteram, no seu nível, essa tentativa de exclusão do sujeito, constitutiva da ciência moderna" (p. 93). Figueiredo e Tenório (2002) afirmam que:

atualmente, o triunfalismo da psiquiatria biológica ameaça reduzir a clínica psiquiátrica à mera aplicaçáo apriorística de condutas: feita a equivalência entre os sintomas observados pelo médico e o diagnóstico determinado nos sistemas de classificação, está dada a conduta, prescindindo-se do sujeito e de suas circunstâncias (p. 31).

Ainda segundo Zarifian (1986/1989), há o perigo de se evocar o diagnóstico psiquiátrico de maneira unívoca e de o utilizarmos de 
forma globalizante. Tal perigo relaciona-se à tendência da psiquiatria biológica de "tratar" os comportamentos que fogem à norma. $\mathrm{O}$ autor indica a necessidade de considerarmos, inclusive, os aspectos socioculturais, pois o que é percebido como "desvio" em uma cultura, pode ser sinônimo de status em outra.

\section{As concepções psicanalíticas e o diagnóstico em psicanálise}

O diagnóstico em psicanálise traz outra perspectiva em relação ao diagnóstico médico. Freud (1913/1996) aponta que ao contrário da medicina, a psicanálise não pode prever um tempo para o tratamento e nem para o diagnóstico, uma vez que prioriza a fala e a escuta do sujeito, e é a partir daí que o diagnóstico será estabelecido e o tratamento orientado.

Se por um lado o estabelecimento do diagnóstico médico influencia as discussões em torno da possibilidade de diagnóstico na psicanálise, por outro, a perspectiva de singularidade do sujeito na teoria psicanalítica indica contradição. Ao diagnosticar qualquer sujeito, estamos classificando-o e colocando-o em determinado grupo, já que todo diagnóstico implica em uma comparação com outros sujeitos que tenham "sintomas" semelhantes (Vieira, 2001). Logo, a delimitação de um diagnóstico parece ir contra a perspectiva psicanalítica ao agrupar o sujeito em uma categoria específica: traz como consequência a perda da singularidade do mesmo e estabelece as classes que apontam grupos de exclusão. Miller (1987) nos diz que a demanda para a clínica psicanalítica é individual, ou seja, parte do próprio sujeito. Em contrapartida, a demanda da psiquiatria provém do contexto social em que o sujeito está inserido, apontando-nos mais um aspecto de exclusão.

Diante disso, contrário à perspectiva médica, em que há a utilização de métodos para a realização de um diagnóstico, a psicanálise prioriza a fala e a escuta qualificada, e dessa forma, ao introduzir a singularidade, origina outra clínica. Kammerer e Wartel (1986/1989) acrescentam: “O diagnóstico, que evidentemente não dispensa apresentação e o modo de contato com o sujeito, funda-se essencialmente em suas queixas subjetivas, emoções, pulsões, comportamentos que ele descreve" (p. 31). A psicanálise trata pela exceção, considerando cada caso, em sua singularidade, como caso único. É justamente o mal que habita cada um e provoca exclusão que a psicanálise acolhe para tratar.

No desenvolvimento da psicanálise Freud e Lacan se serviram de algumas categorias diagnósticas da psiquiatria clássica, apontando para a constituição do sujeito no campo simbólico, sujeito esse que tem sua realidade mediada pelo Outro (Vieira, 
2001). Contudo, esse autor adverte que "todo diagnóstico é uma classificação", pois insere o sujeito em uma classe e fica sujeito ao perigo de segregar sua singularidade em prol de "algumas propriedades que passarão a representá-lo, com todos os efeitos de mortificação que daí advêm" (Vieira, 2001, p. 171). Para Freud, o diagnóstico vai além da ideia de nexo causal. Ele aponta a necessidade da realização das entrevistas preliminares, que dizem respeito aos primeiros contatos com o paciente e são de extrema importância. A partir dessas entrevistas pode-se estabelecer a transferência que permite ao psicanalista localizar a estrutura do sujeito. Freud acrescenta que nas entrevistas preliminares "se deixa o paciente falar quase todo o tempo e não se explica nada mais do que o absolutamente necessário para fazê-lo prosseguir no que está dizendo" (1913/1996, p. 140).

As entrevistas preliminares consistem em permitir que o sujeito fale tudo que lhe venha à mente, uma vez que é a partir da sua fala que o psicanalista estabelece o diagnóstico da estrutura clínica, que orientará o tratamento. As entrevistas preliminares servem justamente para o estabelecimento da transferência, na medida em que no início do tratamento a presença do analista é a simples implicação de sua escuta como condição da fala. Somente depois, "El diagnóstico del sujeto, producido en transferencia, da cuenta de la posición del sujeto en la estructura" [O diagnóstico do sujeito, produzido em transferência, compreende a posição do sujeito na estrutura] (Rubinstein, 2014, p. 3, tradução nossa). Assim, a posição do analista na transferência, implicado na escuta que faz, é fundamental para a construção do diagnóstico.

Se, por um lado, ele é necessário para que o analista tome seu lugar no sintoma do paciente, por outro, não deixa de afetá-lo de modo tão importante que até suas próprias resistências se tornam fonte de dificuldades e erros; assim, o desejo do analista é fundamental tanto no momento de diagnosticar quanto no resto da condução do tratamento. (Monseny, 1995/2001, p. 72).

Em $A$ direção do tratamento e os princípios de seu poder, Lacan pontua que "à medida que se desenvolve uma análise, o analista lida alternadamente com todas as articulações da demanda do sujeito. Mas só deve, como diremos mais adiante, responder aí a partir da posição da transferência" (1958/1998, p. 625). Também assinala que Freud reconheceu o princípio do poder da transferência justamente no ponto onde não o distinguia da sugestão. Contudo, ao mesmo tempo e a partir dos casos que relatou, Freud constatou que tal “... 
poder só lhe dava a solução do problema na condição de não se servir dele, pois era então que assumia todo o seu desenvolvimento de transferência" (Lacan, 1958/1998, p. 603).

No diagnóstico em psicanálise, consideramos que a "doença" ocupa um sentido para o sujeito, que está afastado de sua consciência, mas inserido na trama de seu desejo. A associação livre deve assumir um papel de extrema importância para a escuta desse sujeito, pois é a partir dela que poderemos ter acesso aos seus desejos inconscientes (Priszkulnik, 1998). Assim, não se trata de adaptar o sujeito ao sentido da doença, "mas de lhe mostrar que ela (a bela alma) está mais do que bem adaptada nela, uma vez que concorre para sua fabricação" (Lacan, 1958/1998, p. 602).

\section{O fenômeno e a estrutura}

Embora o fenômeno esteja relacionado à clínica psiquiátrica, o mesmo não é contraditório ao diagnóstico psicanalítico. Ao contrário, é a partir dos fenômenos que podemos ter acesso à estrutura do sujeito (Vieira, 2001). A psicanálise, entretanto, não se utiliza desses fenômenos para classificar o sujeito, mas parte dos mesmos como instrumentos de auxílio no estabelecimento do diagnóstico estrutural. "Apesar de o fenômeno ser a única via de acesso à estrutura, esta lhe confere existência pela organização e pela formatação mundana que lhe oferece" (Vieira, 2001, p. 174).

Então, os fenômenos na clínica psicanalítica não indicam o estabelecimento de um diagnóstico fenomenológico, mas permitem a compreensão da constituição da estrutura clínica, assim como de sua função na subjetividade e de sua dinâmica (Quinet, 2001). Por sua vez, a psicanálise não estabelece diagnóstico fenomenológico, mas preocupa-se com o diagnóstico estrutural, sendo esse aspecto o que indica a grande diferença entre a clínica psiquiátrica e a clínica psicanalítica. Aqui podemos entender o que Freud nos diz ao relacionarmos a psicanálise e a psiquiatria a partir da relação entre histologia e anatomia. A histologia estuda a constituição dos órgãos, e a anatomia se preocupa com a forma desses órgãos. Da mesma forma, respectivamente, são a psicanálise e a psiquiatria: essa se preocupa com o fenômeno enquanto forma que o sintoma apresenta, e aquela com a estrutura constitutiva desse sintoma (Freud, 1917/1996).

Nesse sentido, a relação dos fenômenos com o diagnóstico estrutural nomeia o fenômeno como uma vertente imaginária, simbólica e real. A primeira se manifestaria por "dar" uma roupagem ao sujeito, a segunda, por sua vez, identifica-o e diferencia-o, e a última vertente diz respeito, então, ao circuito do 
gozo ${ }^{2}$ (Vieira, 2001). Assim, os fenômenos devem ser organizados, a fim de possibilitar a delimitação da estrutura clínica. Contudo, "só é possível falar dos fenômenos no a posteriori de sua nomeação, pois só ao serem incluídos na estrutura eles se tornam apreensíveis" (Vieira, 2001, p. 173).

Embora o diagnóstico estrutural envolva os fenômenos que apontam as dimensões imaginária, simbólica e real, esse "só pode ser buscado no registro do simbólico, onde são articuladas as questões fundamentais do sujeito (sobre o sexo, a morte, a procriação e a paternidade) quando da travessia do complexo de Édipo" (Quinet, 2001, p. 76). O psicanalista, assim, deve estar atento aos fenômenos, já que esses auxiliam na compreensão da forma como o sujeito vivenciou a travessia do complexo de Édipo, ponto essencial em que se localiza a formação da estrutura clínica do sujeito.

Compreendemos então que o diagnóstico estrutural, diferentemente do diagnóstico fenomenológico, coordena-se a uma nomeação que ao invés de inserir o sujeito em um grupo, marca sua singularidade. Diagnosticar na psicanálise deve ter como objetivo tocar um modo singular de gozo, operação que não faz grupo nem classe (Vieira, 2001, p. 176).

O autor lembra-nos ainda que o diagnóstico vem nomear um ponto onde a estrutura abre-se ao real, possibilitando que o analista ocupe seu lugar e o sustente diante da transferência. Cabe, pois, ao psicanalista oferecer a possibilidade de o sujeito mostrar-se enquanto tal, abrindo-lhe a oportunidade de falar, assim como de ser escutado enquanto outro. Para tal, deve-se preocupar não só com o presente e com os fenômenos que se apresentam nesse tempo, mas possibilitar ao sujeito a percepção de seu passado e de seu futuro. Essa perspectiva não deve ser trabalhada de forma linear, pois os aspectos temporais só podem ser apreendidos por meio da observação e entendimento das ideias inconscientes que são atemporais.

\section{Um sujeito para além da psiquiatria e da psicanálise}

Faremos o relato de um caso clíni$\mathrm{CO}^{3}$ de psicose, atendido em um serviço público de saúde mental tipo CAPS III (Centro de Atenção Psicossocial), da cidade de Belo Horizonte, Minas Gerais. Visamos elucidar a trajetória de segregação vivida pelo sujeito em várias instituições, inclusive na própria instituição onde aderiu ao tratamento.

Otto chegou ao referido serviço em 2010, encaminhado por um Hospital Psiquiátrico de Belo Horizonte, onde ficara internado dos 16 aos 18 anos. Teve alta a pedido de sua mãe de criação. Otto recebeu vários diagnósticos, tais como: Esquizofrenia Hebefrênica, Esquizofrenia Paranoide, Psicose 
orgânica, Retardo mental leve e Epilepsia tipo "Grande mal". Além disso, apresentava Hipertensão Arterial Sistêmica, Diabetes Mellitus 2 e Obesidade Mórbida.

Ele carregava um histórico de graves condutas agressivas. Aos 13 anos, foi expulso da escola em razão de uma agressão à professora. Aos 15, recebeu alta administrativa da instituição onde fazia tratamento psiquiátrico, por ferir gravemente os olhos de uma médica. Marcado pela segregação, seu movimento oscilava entre ficar imerso nas instituições, convocando-as na totalidade, ou ser expulso, apontando-as na posição de impotência. O diagnóstico que prevalecia entre as instituições circulava em torno da deficiência mental e dos sintomas de impulsividade que corroboravam uma hipótese orgânica deficitária.

$\mathrm{Na}$ primeira passagem pelo CERSAM ${ }^{4}$, Otto apresentou uma demanda insistente reativa às restrições de uma dieta para diabéticos. Queria comer toda hora, levava guloseimas de casa e pedia comida o tempo todo. Frente às negativas, dizia: "Quero alta ou vir todos os dias". Recebeu alta e retornou em menos de um mês, após ser levado pela Polícia Militar para outro hospital psiquiátrico de Belo Horizonte. Ele havia quebrado, com uma barra de ferro, o frigorífico de um açougue próximo à sua casa, onde lhe foi negado um pedaço de carne. Foi agredido pelo açougueiro e agrediu pessoas. Sobre seu ato, Otto relatou que haviam uns rapazes próximo ao açougue que sempre o"zoavam" e, com isso, ficou nervoso.

Logo depois ele quebrou os vidros e jogou no chão o balcão térmico do refeitório do Cersam. Disse: "Pode chamar a polícia para mim, chama mesmo...". Apresentou falas hostis e ameaçadoras ao seu psiquiatra, repetindo insistentemente a intenção de matá-lo, com planos anunciados. Diante disso, a equipe decidiu pela mudança de referência ${ }^{5}$ psiquiátrica. Entretanto, logo o rapaz recebeu alta do serviço, a pedido de sua mãe, que havia conseguido uma vaga para ele em um terceiro hospital psiquiátrico.

Meses depois, Otto retornou. Em seu primeiro contato com a referência, disse que pediu para ser internado e sua mãe achou bom. A analista perguntou-lhe o motivo e ele respondeu: "Tudo que some e estraga em minha casa é minha culpa. Já conversei, mas não adianta nada, sempre recai em mim" (a acusação). Imediatamente perguntou se a analista iria expulsá-lo do Cersam, ao que ela respondeu que ele havia acabado de chegar, e ela estava acolhendo-o. Esse segundo momento foi marcado por inúmeros atos de agressividade e violência,

288 Estilos clin., São Paulo, v. 20, n. 2, mai./ago. 2015, 279-295. 
inclusive com ameaças direcionadas a sua, então, referência psiquiátrica. Quando interpelado, perguntava se seria mandado embora. A analista respondia que não, pois ele estava ali justamente para tratar de seus problemas.

Naquela situação, a analista solicitou uma supervisão clínica para discussão do caso com toda a equipe. Na supervisão, foi novamente realizada a mudança de referência psiquiátrica. Além disso, apareceram elementos que indicavam um diagnóstico de psicose: sua posição persecutória e a fixação em rádios. A família queixava-se que até aquele momento somavam-se mais de 12 aparelhos de som que Otto quebrara. Ele atribuía a responsabilidade a outras pessoas, insistindo na compra de um novo aparelho.

Sobre a história familiar sabe-se que a mãe biológica de Otto era compał nheira homoafetiva de sua mãe, sendo ele fruto de uma traição. Logo após ser acolhida na residência de sua mãe de criação, sua mãe biológica engravidou dele "na rua". Ela era usuária de drogas e abandonou-o quando tinha seis anos de idade. A princípio Otto contou que sua mãe biológica é "ladra e usuária de drogas". Disse que a mãe adotiva (que doravante chamaremos de "mãe") o criara desde bebê e que o marido dela havia dito: "ou fica comigo ou com esse bebê". A mãe ficou com a criança e o marido foi embora. Depois, em várias cartas, a versão de Otto foi diferente: sua mãe viu que a mãe biológica ia "passá-lo para uma outra mulher, entrou na frente e pegou-o para criar". Otto residia com a mãe e a atual companheira homoafetiva da mesma. Ele não tinha notícias de sua mãe biológica, não sabia quem era seu pai e nem tinha notícias de irmãos. Demonstrava ciúmes da relação de sua mãe com a companheira.

A mãe, por sua vez, apresentava uma posição ambígua em relação a Otto, dizendo que o amava, mas, ao mesmo tempo, afirmava que não tinha condições de criá-lo, por sofrer de vários problemas de saúde. Ela oscilava entre uma superproteção que o infantilizava - na qual inexistiam limites e o cuidado passava pelo campo das necessidades físicas - e uma impotência que o expulsava, delegando o cuidado dele ao Estado. Ela tomava Otto como um objeto que ela podia incorporar ("vocês não dão conta dele, eu cuido") e expulsar ("eu não dou conta dele, abriguem-no").

Otto respondia onde o Outro o esperava, reagia no espelho, repetindo o agressivo, o ladrão, o que quebrava e estragava. Bastava uma palavra vinda do outro, rememorando passagens ao ato ocorrido anteriormente, e Otto passava ao ato. Havia algo que apontava uma parceria entre os dois, calcada em um movimento de vida e morte. Certa vez ela disse à psiquiatra: "sedado, eu dou conta dele". Interpretamos essa posição da mãe como um desejo de reter, em seu controle, deixá-lo ativo ou mortificado como seu objeto.

A escuta clínica possibilitou um cálculo na direção do tratamento para além dos fenômenos de agressividade e impulsividade que se apresentavam. A 
construção do caso clínico deu-se a partir da posição estrutural do sujeito. Assim, estreitamos nosso contato com a família para afinarmos alguns acordos e trabalharmos com a mãe os efeitos de sua posição no comportamento do filho. Tentávamos fazer do outro um outro menos maciço, produzindo um intervalo entre Otto e a mãe. Foi acordado com ambos e ele mudou-se para um cômodo na parte de baixo da casa, construindo-se aí uma distância mínima necessária à boa convivência e uma dimensão de responsabilidade dele próprio com sua independência.

Orientada pela clínica psicanalítica, a direção do tratamento precisava incidir justamente sobre o movimento de segregação: nem dentro, nem fora, nem todo dentro, nem todo fora. $\mathrm{Na}$ posição de acolher o impossível e o pior de Otto, a analista precisou encontrar o bom lugar onde ele pudesse se inscrever. $\mathrm{O}$ saber não estava do lado da instituição e a invenção de um lugar possível apontava para uma extimidade íntima ou uma intimidade êxtima.

$\mathrm{Na}$ construção do caso surgiu, como uma estratégia de abordagem que incluísse a família e a comunidade, a entrada de um brincante com a "mala de recursos lúdicos", do Serviço de Proteção à Pessoa Portadora de Deficiência. O brincante conseguiu captar Otto na cena de sua rua, envolto por crianças, e propôs a construção de um brinquedo. O brinquedo escolhido por Otto consistiu em uma bola oval atravessada por duas cordas, onde duas pessoas coordenam a abertura e fechamento das cordas, por onde a bola vai e vem. Otto levou esse objeto para o Cersam, em uma sacola, como algo precioso, para mostrar à analista. A resposta de Otto confirmou a direção do tratamento, pois foi possível recolher desse objeto, que poderíamos demarcar um dentro e um fora, e uma possibilidade de ir e vir.

Como efeito do vai e vem, objeto construído, ele passou a circular pela cidade e chegava ao serviço por conta própria, demandando acolhimentos pontuais. Comparecia em horários e dias inesperados, convocando, na equipe, o manejo com a contingência na instituição. Nesse momento, a analista levou o caso novamente para a supervisão com o objetivo de avaliar a condução do tratamento, pois era preciso construir um cálculo de riscos e um consentimento da equipe quanto a esse movimento de Otto. Como resultado, traçamos estratégias fora dos protocolos pré-definidos, frente à dimensão da surpresa que seu aparecimento convocava. Era o sujeito aparecendo no ir e vir, como o seu vai e vem. 


\section{A escuta da linguagem}

Nas sessões, Otto trazia fragmentos de programas infantis, cantava, fazia trocadilhos, adivinhações e trazia jogos de memória para jogar com a analista. Ele também solicitava que a analista escrevesse cartas para sua mãe, por meio das quais agradecia a ela pelo fato de tê-lo "pegado para criar", pedia desculpas pelas agressões que já fizera e declarava seu amor filial. Um elemento de ligação que surgiu, quase como uma linguagem própria das sessões, foram músicas cantadas em coro com a analista. Cantar apaziguava Otto que, paralelamente, falava dos seus rádios e conversava sobre sua vida.

Otto passou a pedir dinheiro às pessoas na rua para comprar um microsystem, e pediu à analista para escrever uma "carta de apresentação", a fim de mostrar às pessoas a quem abordava. Na carta, esclarecia que era pessoa de família, que não era ladrão, nem usuário de drogas e bebida. Dizia qual destino daria ao dinheiro e falava sobre a função das músicas para o acalmar. Fornecia nome e telefone de sua mãe, como forma de garantir credibilidade. Otto circulou com a carta e comprou seu microsystem, como também CDs de músicas específicas dos programas de TV de que mais gostava, principalmente da Galinha Pintadinha e Patati Patatá.

Sendo elemento de amarração, Otto ia ao Cersam com uma mochila, seu aparelho microsystem e seus
CDs. Com esses objetos acabava fazendo laços com outros pacientes, mas não sem turbulências: devido à monotonia e repetições de suas músicas, alguns aparelhos foram estragados, perdidos, roubados e trocados. Entretanto, Otto logo comprava outro. A analista, ao explorar como seus aparelhos estragavam, recolheu um ponto que se repetia: o defeito era sempre no "aparelho de leitura": arrancado, estragado ou apagado. Essa "leitura" se referia ao visor que permitia escolher, pelo número, a faixa de música desejada segundo a legenda do CD.

$\mathrm{O}$ microsystem passou à categoria de objeto precioso, a ponto de ser preservado em detrimento da própria vida. Certa noite, Otto se dirigiu ao Serviço de Urgência Psiquiátrica (SUP`) demandando "pernoitecer". Diante da negativa, Otto atuou: deitou-se no meio da rua, foi atropelado e quebrou três costelas. Antes, porém, colocou o microsystem no banco do ponto de ônibus. Ao ser interrogado pela analista, ele respondeu que colocara o aparelho no local para evitar que se quebrasse.

Em razão da gravidade desse caso, que fazia emergir o real traumático na prática clínica, perguntamo-nos: Qual é a posição da analista ao manejar o caso, para estar presente no campo de Otto, fazendo o furo necessário para o sujeito existir (sem que ele recorresse à agressão para se separar do outro)? Qual posição a analista ocupa frente à família e à equipe institucional para transmitir um saber fazer nesse caso? 


\section{Considerações finais}

Partindo da prática clínica para fomentar a discussão sobre o diagnóstico em saúde mental, seja ele psiquiátrico ou psicanalítico, podemos nos perguntar: Em que o diagnóstico ajudou na condução do tratamento? Acreditamos que o caso clínico escolhido ressalta a tensão provocada pela necessidade de definição diagnóstica entre campos de saber diferenciados: a psicanálise e a psiquiatria.

Observamos que o sujeito "Otto" chega marcado por vários diagnósticos psiquiátricos que precipitaram sua segregação. De saída, as nomenclaturas excluíam o sujeito, privilegiando a dimensão sintomática, sem, no entanto, possibilitar alguma via de tratamento. A entrada da escuta psicanalítica favoreceu o acolhimento do sujeito mesmo diante de sua precariedade simbólica e de sua tendência agressiva. Para além da querela diagnóstica, foi o lugar conferido a esse sujeito que possibilitou as operações clínicas, permitindo uma passagem da condição do intratável para o tratável.

Quando a analista interpela Otto a respeito de seus atos agressivos, ao mesmo tempo lhe confere um lugar, justamente no momento em que ele pergunta se seria expulso do serviço. Ao dar a voz a Otto, a analista possibilita a ele, enquanto sujeito, poder falar do seu próprio sofrimento e, consequentemente, inaugura um novo momento na história dele na instituição.

O pedido de uma supervisão clínica por parte da analista, envolvendo toda a equipe do serviço, esvaziou sua posição de saber sobre o caso e a ênfase exclusiva no diagnóstico, seja ele fenomenológico ou estrutural. Ocupando essa posição, a analista consentiu com o não saber, permitindo que toda a equipe pudesse saber não saber. A partir da construção do caso, foi possível traçar uma direção para o tratamento por meio da disponibilidade de escuta.

A posição de segregação girava em torno da história familiar e da relação imaginária maciça com a mãe adotiva. Essa relação se reproduzia nos serviços por meio de graves passagens ao ato dirigidas aos técnicos. Privilegiando a noção de direção do tratamento a partir do estabelecimento de uma "zona transferencial", o diagnóstico estrutural pôde surgir para além dos fenômenos que se apresentavam. A analista pôde se posicionar como um outro eclipsado na cena, para que desse lugar pudesse dirigir os fenômenos paranoicos. Como afirma Lacan (1948/1998) em A agressividade em psicanálise, "longe

292 Estilos clin., São Paulo, v. 20, n. 2, mai./ago. 2015, 279-295. 
de atacá-lo de frente, a maiêutica analítica adota um rodeio que equivale, em suma, a induzir no sujeito uma paranoia dirigida" (p. 112). Foi possível, no corpo a corpo da clínica, secretariar Otto na escrita das cartas e nas canções, ao emprestar-lhe as mãos e a voz.

No primeiro momento, o real insuportável da violência provocava a expulsão ou imersão integral na instituição. No segundo momento, o acolhimento e escuta do mínimo de linguagem produzida pelo sujeito permitiu uma flexibilização de sua permanência no serviço. Tem-se algo da ordem de uma exterioridade íntima e uma intimidade êxtima como um lugar possível para o sujeito. Mais à frente, essa escuta viabilizou o apaziguamento da agressividade pela via dos objetos como o vai e vem, o microsystem e os CDs, por exemplo. Trata-se da tentativa de fazer com que esses objetos permitam ao sujeito circular estabelecendo laços sociais.

Concluímos que é preciso saber servir-se do diagnóstico psiquiátrico e psicanalítico sem deixar-se seduzir sobre os efeitos segregadores que suas certezas proporcionam. Como nos sugere Vieira (2001), "trataríamos o diagnóstico tanto como um mal necessário quanto como um bem perigoso, que deve ser buscado, mas jamais inteiramente alcançado" (p. 172). Essa orientação propicia o estabelecimento de operações clínicas sobre os fenômenos apresentados. Pois, para além do diagnóstico, é a direção do tratamento, estabelecido sob transferência, e a construção do caso clínico que possibilitam o aparecimento do sujeito no que ele tem de mais singular.

THE SOVEREIGNTY OF THE CLINIC: BEYOND THE DIAGNOSIS IN PSYCHLATRY AND PSYCHOANALYSIS

\section{Abstract}

In this article we will point out the differences between the psychiatric diagnosis of biological thinking and psycboanalytic diagnosis. To do so, some aspects of classical psychiatry and biological psychiatry will be presented, considering the influence psychopathology in defining the diagnostic manuals and hence the diagnostics currently used in psychiatric clinic. We will discuss the purpose of the structural diagnosis under transfer to point the direction of the treatment in psychoanalysis and to point the possibilities of approximation between diagnoses, considering the phenomenon and the structure. Lastly, we will use the study of a clinical case with diagnostic appointments from both sides. Index terms: psychiatry; psychoanalysis; diagnosis; direction of treatment.

LA SOBERANÍA DE LA CLÍNICA:

MÁS ALLÁ DEL DIAGNÓSTICO EN PSIQULATRÍA Y PSICOANÁLISIS

\section{Resumen}

En este artículo se intenta señalar las diferencias entre el diagnóstico psiquiátrico biológico y el diagnóstico psicoanalitico. Para ello, se presentan algunos aspectos de la psiquiatría clásica y de la psiquiatría biológica, teniendo en cuenta la influencia de la psicopatología en la definición de los manuales de diagnóstico y, por lo tanto, en los diagnósticos que se utilizan actualmente en la clínica psiquiátrica. Se discute el propósito del diagnóstico estructural en transferencia, para trazar la dirección de tratamiento en psicoanálisis, señalando las posibilidades de aproximación entre estos diagnósticos, teniendo en cuenta el fenómeno y la estructura. Por último, se utiliza el estudio de un caso clínico con nombramientos diagnósticos de ambas vertientes.

Palabras clave: psiquiatría; psicoanálisis; diagnóstico; dirección de tratamiento. 


\section{REFERÊNCIAS}

Birman, J. (2001). Desposessão, saber e loucura: sobre as relações entre psicanálise e psiquiatria hoje. In A. Quinet (Org.), Psicanálise e psiquiatria: controvérsias e convergências (pp. 21-29). Rio de Janeiro, RJ: Rios Ambiciosos.

Chemama, R. (Org.) (1995). Larousse: dicionário de psicanálise (F. F. Settineri, trad.). Porto Alegre, RS: Artes Médicas.

Dalgalarrondo, P. (2008). Psicopatologia e semiologia dos transtornos mentais (2a. ed.). Porto Alegre, RS: Artmed.

Figueiredo, A. C., \& Tenório, F. (2002). O diagnóstico em psiquiatria e psicanálise. Revista Latinoamericana de Psicopatologia Fundamental, 5 (1), 29-43. Recuperado de http://www. fundamentalpsychopathology.org/uploads/files/revistas/volume05/n1/o_diagnostico_em_psiquiatria_e_psicanalise.pdf.

Freud, S. (1913/1996). Sobre o início do tratamento: novas recomendaçôes sobre a técnica da psicanálise I. In Obras psicológicas completas (Vol. XII, pp. 135-158). Rio de Janeiro, RJ: Imago.

Freud, S. (1917/1996). Conferência XVI - psicanálise e psiquiatria. In Obras psicológicas completas (Vol. XVI, pp. 251-263). Rio de Janeiro, RJ: Imago.

Kammerer, T., \& Wartel, R. (1986/1989). Diálogo sobre os diagnósticos. In A querela dos diagnósticos (L. Forbes, trad., Coleção Cliniques, pp. 27-44). Rio de Janeiro, RJ: Jorge Zahar.

Lacan, J. (1948/1998). A agressividade em psicanálise. In Escritos (V. Lúcia, trad., pp. 104-126). Rio de Janeiro, RJ: Jorge Zahar.

Lacan, J. (1958/1998). A direção do tratamento e os princípios de seu poder. In Escritos (V. Lúcia, trad., pp. 591-652). Rio de Janeiro, RJ: Jorge Zahar.

Miller, J-A. (1987). A psicanálise e a psiquiatria (J. Forbes, W. B. França, trads.). FALO - Revista do Campo Freudiano no Brasil, 1, 113-124.

Monseny, J. (1995/2001). A ética psicanalítica do diagnóstico. In A. Quinet (Org.), Psicanálise e psiquiatria: controvérsias e convergências (C. S. Freire, trad., pp. 69-72). Rio de Janeiro, RJ: Rios Ambiciosos.

Priszkulnik, L. (1998). As entrevistas diagnósticas em Psicanálise. Revista Psychê, 2(2), 17-23.

Quinet, A. (2001). Como se diagnostica hoje? In A. Quinet (Org.), Psicanálise e psiquiatria: controvérsias e convergências (pp. 73-77). Rio de Janeiro, RJ: Rios Ambiciosos.

Rubinstein, A. (2014). Algunas cuestiones relativas al diagnóstico em psicoanálisis. 1-8. Recuperado de http://ea.eol.org.ar/03/es/textos/txt/pdf/textos_rubistein.pdf.

Santos, A. A. S. (2008). Coerentismo epistemológico e o diagnóstico psiquiátrico. Revista de Neurobiologia, 71(3), 27-33. Recuperado de http://www.neurobiologia.org/ex_2008.2/ Microsoft\%20Word\%20-\%204_Epistemol_Adelson_OK_.pdf.

Sauret, M-J. (2003). A pesquisa clínica em psicanálise. Psicologia USP, 14(3), 89-104. doi. org/10.1590/S0103-65642003000300009

Vieira, M. A. (2001). Dando nome aos bois: sobre o diagnóstico na psicanálise. In A. C. Figueiredo (Org.), Psicanálise: pesquisa e clínica (Vol. 1, pp. 171-181). Rio de Janeiro, RJ: IPUB/UFRJ.

Zarifian, É. (1986/1989). Um diagnóstico em psiquiatria: para quê? In É. Zarifian, A Querela dos Diagnósticos (L. Forbes, trad., Coleção Cliniques, pp. 45-51). Rio de Janeiro, RJ: Jorge Zahar.

\section{NOTAS}

1. Cada teoría recorta el campo particular de los fenómenos clínicos de una manera diferente.

294 Estilos clin., São Paulo, v. 20, n. 2, mai./ago. 2015, 279-295. 
2. Gozo é um termo introduzido por Lacan em continuidade às elaborações de Freud sobre a satisfação da pulsão, embora sejam noçóes distintas. Segundo Chemama, "o gozo refere-se ao desejo, e precisamente ao desejo inconsciente... pelo próprio fato de que nosso desejo está constituído pela nossa relação com as palavras" (Chemama, 1995, p. 90).

3. Para fins de preservação da identidade, o paciente recebeu um nome fictício e os nomes das instituiçóes secundárias foram suprimidos.

4. Em Belo Horizonte os serviços tipo CAPS III são nomeados Cersam (Centro de Referência em Saúde Mental).

5. Nos Cersam os usuários são acompanhados por um técnico de nível superior (psicólogo, assistente social, terapeuta ocupacional ou enfermeiro) e um médico psiquiatra que tem a função de referenciar o caso.

6. Serviço de Urgência Psiquiátrica que funciona como referência noturna para os Cersam de Belo Horizonte.

natiraquel.psi@gmail.com

Rua Noroeste, 536 32678-350 - Betim - MG - Brasil.

paulabrantf@gmail.com.br Rua Benjamin Jacob, 397/802 30441-146 - Belo Horizonte - MG - Brasil.

Recebido em novembro/2014. Aceito em junho/2015. 